\title{
MRS-Taiwan Initiates the Chinese Federation of Materials Societies and Other Activities During the Year of Its 30th Anniversary
}

In May, the Materials Research SocietyTaiwan (MRS-T) became the founding member of the Chinese Federation of Materials Societies in Taiwan. The Federation consists of 15 member societies, including societies or associations for Vacuum Technology, Polymer, Magnetic Technology, Foundry, Advanced Materials, Mining and Metallurgy, Materials Science, Welding, Forging, Heat Treatments, Electronic Devices and Materials, Corrosion Engineering, Ceramics, Powder Metallurgy, and Nondestructive Testing. The ultimate purpose of the Federation is to consolidate resources to promote materials science and technology in Taiwan. Near-term goals include information exchange through publications of the member societies, establishment of a joint website, joint meetings, and joint publications. The president of MRS-T and chair professor of materials science and engineering at National Tsing Hua University, L.J. Chen, was elected the president of the Federation for a one-year term. The

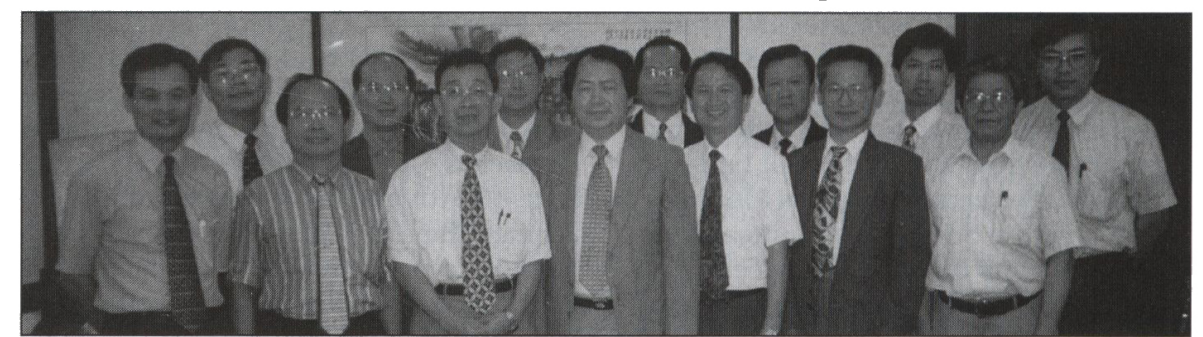

Presidents of Member Societies of the Chinese Federation of Materials Societies in Taiwan.

address of the joint website is 140.114 . $18.41 / \mathrm{cfmst} /$. The page includes Federation news and information on the member societies as well as Internet links.

This year marks the 30th Anniversary of MRS-T. To commemorate the event, the Society will publish a special volume on the Development of Materials Research and Education in Taiwan. Responses to the invitation for contributions have been overwhelming. The special volume will con- sist of articles from academic and research institutions in materials and many materials manufacturers as well as a number of excellent individual accounts. As the development of materials research and education in Taiwan is roughly parallel to that of MRS-T, the special volume will undoubtedly be of significant historical value. The publication is expected to appear by the time of the MRS-T Annual Meeting in November.

\section{Nove"Quick Flange" model addition to our Mini Gate Vacuum Valves}

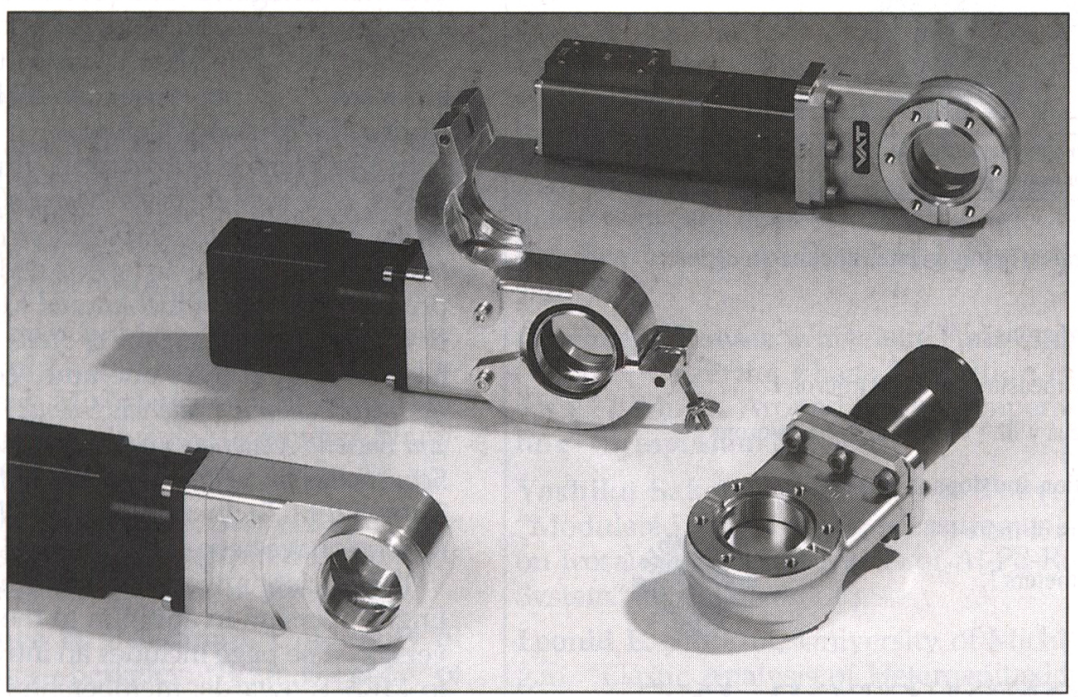

Integrated into the valve body are:

- Clamp Assembly

- ISO Centering \& Seal

Available in sizes 16, 25, $40 \& 50 \mathrm{~mm}$ I.D.

\section{Request your new} Catalog 2000 today

VAT, Inc., 500 West Cummings Park, Woburn, MA 01801

Tel 781-935-1446 Fax 781-935-3940

e mail: usa@vatvalve.com http://www.vatvalve.com

\section{A6 E}


The Annual Meeting will be held from November 20 to 21 at Tatung Institute of Technology, Taipei. The Meeting will be the first ever joint meeting for MRS-T, Chinese Societies for Powder Metallurgy, and Chinese Society for Foundry. Twelve symposia will be held in parallel and proceedings will be published for each symposium. Several prestigious awards will be given during the plenary session of the Meeting.

The Fracture Science Committee of the Society held its 5 th Biennial Meeting on Fracture Science in Nantou from March 28 to 29 . The Meeting attracted about 400 participants across the spectrum of academics and research institutions as well as industry. In addition to individual oral presentations, several panel discussions on local industrial needs were organized.

Within the International Union of Materials Research Societies (IUMRS), the Society has actively promoted the participation of the International Conference on Electronic Materials (ICEM) held in Cheju, Korea in August and the International Conference in Asia (ICA) held in Bangalore, India in October as well as the International Conference on Advanced Materials (ICAM) in Beijing, China next June. The Society is also helping to organize the U.S.-Asia Pacific Workshop on Materials to be held in Hawaii in November.

The Society continues to publish $\mathrm{Ma}$ terials Bulletin, a quarterly newsletter; Chinese Journal of Materials Science, a quarterly archival journal mainly in Chinese;
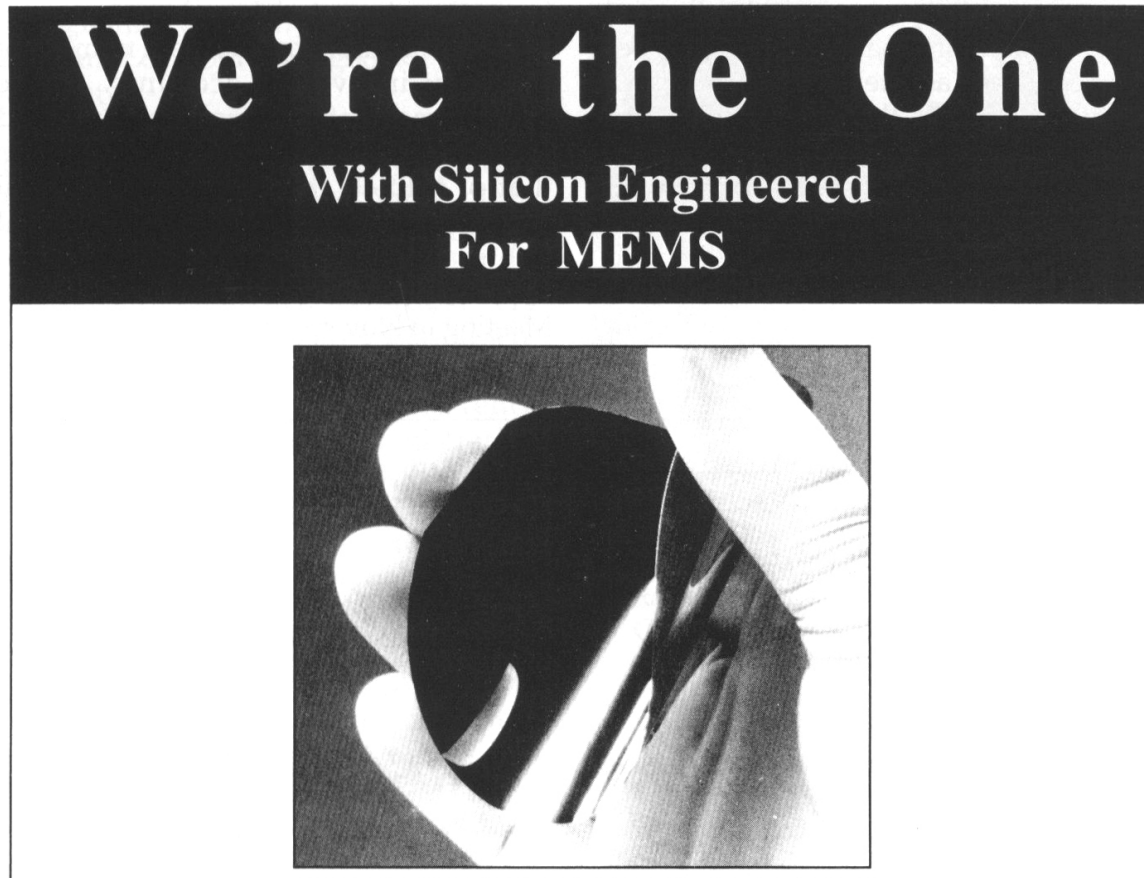

A $10 \mu$ thin single crystal silicon membrane manufactured at Virginia Semiconductor, Inc.

- THINK 5 micron thin, $<100>$ silicon membranes or any greater thickness needed; either $\mathrm{Cz}$ or Fz silicon!

- THINK $<110>$ Fz silicon as thin as 100 microns !

- THINK Silicon membranes accurately measured at \pm 1.0 micron !

- THINK Double side polished surfaces with (TTV's) at $\leq 2.5$ microns !

- THINK Tailoring to your orientation and dopant needs !

- THINK Batch sizes of 10 wafers or more !

- THINK 50.8 - 100.0 mm diameters !

- THINK

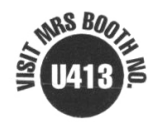

VIRGINIA SEMICONDUCTOR, INC.

1501 Powhatan Street, Fredericksburg, VA 22401 PH: (540) 373-2900 FAX: (540) 371-0371

Nonecore VISA Now Accepting

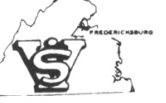

Circle No. 42 on Reader Service Card.

and Materials Chemistry and Physics (MCP), a monthly international journal published jointly with Elsevier. In July, $M C P$ received the Outstanding Journal Award from the National Science Council for the fifth consecutive year. In the same month, $M C P$ published Proceedings of Symposium H on Materials Synthesis and Modification by Ion and / or Laser Beams of the 4th IUMRSICA, Chiba, Japan as a special issue. A special issue in honor of the 70th birthday of S. Somiya of Teikyo University of Japan will be published early next year.

The Society offers three new web courses on Thermodynamics, Materials Science, and Crystallography and Diffraction in the academic year of 1997-1998. The courses were added to the repositories of web courses on Electron Microscopy for Materials, Electronic Materials, and Microelectronic Materials and Processing offered in the academic year of 1996-1997. In the coming academic year, web courses on Materials and Civilization, Solid-State Physics, and Materials Analysis will be introduced. The address of the website is / pilot.mse.nthu.edu.tw/.

In September, four short courses will be launched as parts of the Materials Science Month Activities sponsored by MRS-T. The four short courses are on Nanostructured Materials, Micromechanical and Electrical System Materials Technology, Liquid Crystal and Polymer Optoelectronic Materials Technology, and Aluminum Alloy and Processing. Each course will feature four lectures for a total of 12 hours.

With a grant from the Ministry of Education, MRS-T is sponsoring a Web Page Design Contest for college students. The two categories are (1) materials science and engineering and (2) special topics on materials. The competition has attracted 20 entries. Awards will be given during the Annual Meeting.

In the area of publication, three textbooks, Materials Analysis; Materials Laboratories, Volume 1; and Microelectronic Materials and Processing are scheduled to be in print by the time of the Annual Meeting in November. The Handbook of Steels will also be published at the same time. Textbooks on Introduction to Materials Science; Materials and Society; Materials Laboratories, Volume 2; Semiconductor Industry and Manufacturing; Thin Film Technology; and Electronic Materials have been commissioned.

The Society's website now features an English version in addition to the Chinese version. The page includes an introduction to MRS-T; awards; membership; publications; materials-related job information in Taiwan; materials-related university, college, and research institutions in Taiwan; and information links. The website address is / www.csms.nthu.edu.tw/.

LIH J. CHEN

President, MRS-Taiwan 